\title{
LOS INDOAMERICANISMOS EN EL TESORO DE COVARRUBIAS
}

El Tesoro de la lengua castellana o española del licenciado don Sebastián de Covarrubias Orozco $^{1}$ es -bien se sabe- el primer gran diccionario etimológico de nuestro idioma. Con anterioridad a él, sólo se habían hecho ensayos particulares de carácter etimológico limitados a una sola lengua - el árabe, por lo general- o de muy reducido alcance. La mayor parte de ellos, además, no había llegado a imprimirse nunca. A la luz pública habían salido, en 1505, el Vocabulista aravigo en letra castellana de fray Pedro de Alcalá, y en 1565 la "Declaración de algunos vocablos" que Alejo Venegas incluyó -como último capítulo- en su Agonía del tránsito de la muerte; pero el primero se limita a recoger voces de posible origen árabe exclusivamente, y el segundo atiende sólo a algunos vocablos "escuros... que en el presente libro del tránsito por diversos capítulos están esparzidos". También se había publicado, antes de que apareciera el Tesoro de Covarrubias, el magnífico tratado Del origen y principio de la lengua castellana de Bernardo de Aldrete ${ }^{2}$, cuya contribución etimológica se reduce a la presentación de varias breves listas alfabéticas de voces a que Aldrete supone origen griego, hebreo, germánico o arábigo. A las palabras de este último origen atiende exclusivamente Francisco López Tamarid en su "Compendio de algunos vocablos arábigos introduzidos en la lengua Castellana" (Granada, 1585) ${ }^{3}$, simple lista de arabismos sin indicación del étimo correspondiente; tanto López Tamarid como Aldrete se sirvieron profusamente del Vocabulista aravigo de fray Pedro de Alcalá ${ }^{4}$. A la toponimia de origen árabe dedicó fray Diego de Gua-

1 Todas las citas y remisiones que aquí haga se referirán a la edición preparada por Martín de Riquer, Barcelona, 1943.

2 Roma, 1606. Cito por la edición facsimilar de Lidio Nieto Jiménez, Madrid, 1972.

3 Los reprodujo Gregorio Mayáxs y Siscar en sus Origenes de la lengua española, pp. 194-213 (cito por la edición de Madrid, 1873).

4 Paladinamente lo declara Aldrete: "me aprouecho del arte, $\mathrm{i}$ vocabulista 
dix buena parte de su Recopilación de algunos nombres arábigos... ${ }^{5}$, la cual -aunque dispuesta para la imprenta en 1593- no llegó a publicarse, no obstante lo cual fue bien conocida por Sebastián de Covarrubias, quien declara haberse servido de "algunos escritos" de fray Diego ". También a la toponimia y a la onomástica dedica lo mejor de sus esfuerzos el licenciado Andrés de Poza, en cuyo tratado De la antigua lengua, poblaciones y comarcas de las Españas $^{\top}$ se hallan además curiosas etimologías de base germánica (cap. X), hebrea (caps. III y IV), griega (cap. VIII) y especialmente vascongada.

Inéditas quedaron otras obras de gran aliento y de más amplios alcances que, por sus fechas de preparación, habrían precedido al Tesoro de Covarrubias en el quehacer etimologizante. En especial, la del doctor Francisco del Rosal sobre el Origen y etimología de la lengua castellana ${ }^{8} \mathrm{y}$, en menor medida, las Etimologias españolas que Mayáns ${ }^{9}$ atribuyó a Francisco Sánchez de las Brozas, y el Tratado de etimologias de voces castellanas del licenciado Bartolomé Valverde ${ }^{10}$.

Así pues, el Tesoro de Covarrubias (1611) puede ser considerado el primer diccionario etimológico general de la lengua castellana digno de tal nombre. Aunque tal vez el calificativo que mejor le correspondería sea el de enciclopédico. No obstante que su autor declara reiteradamente que su propósito fundamental "no es tratar las materias ad longum, sino tan solamente las etymologías de los vocablos" ${ }^{11}$, muchas veces parece olvidarse de ello para de-

(assi llama a su vocabulario) del Padre Frai Pedro de Alcalá de la Orden de San Hieronimo, que aura cien años, que lo compuso" (Del origen, p. 363).

5 Cf. Conde de la Viñaza, Biblioteca histórica de la filologia castellana, Madrid, 1893, núm. 790, pp. 814-815.

- En la advertencia "Al Letor" puesta al frente de su Tesoro, refiriéndose a las fuentes utilizadas con relación a la lengua árabe, precisa: "Yo he consultado a Diego de Urrea, intérprete del Rey nuestro señor, y visto algunos escritos del padre Guadix: de ambos me he aprovechado, y de algunos otros que cito en diversos lugares".

7 Impreso en Bilbao en 1587. Cito por la edición de Ángel Rodriguez Herrero, Madrid, 1959.

8 Manuscrito listo para la imprenta en 1601 , en que se atiende al posible origen latino, griego, hebreo, arábigo, prerromano ("vizcaíno"), germánico ("godo"), francés, italiano, alemán, inglés y aun americano de las palabras de la lengua castellana.

9 Cf. Origenes ed. cit., p. 350. La Viñaza registra una copia conservada en la Biblioteca de la Real Academia (cf. núm. 788).

10 Con atención al latín, griego, árabe y, especialmente, hebreo, "fuente y madre de todas" las lenguas (cf. LA ViÑazA, col. 1625).

11 S.v. candela. Cf. además: "no me detendré en estender esta materia, sino acudir a mi instituto, que es investigar las etimologías de los vocablos" (s.v. 
dicarse a reunir en su obra todos los conocimientos de la época en torno a los conceptos seleccionados ${ }^{12}$. El modelo general de su trabajo fue, en cierta medida, las Etimologias de San Isidoro, que Covarrubias invoca como justificadoras de su propia obra en la dedicatoria al Rey puesta al frente del Tesoro. Que es, además, el primer diccionario "puro" del español, por cuanto que en él "ya no se trata de servir a la utilidad práctica de la traducción, sino a intereses múltiples de curiosidad erudita y ciencia pura" ${ }^{13}$.

No obstante sus indudables méritos, el diccionario de Covarrubias ha provocado juicios muy negativos de censores excesivamente severos. Entre ellos, el de Mayáns y Sisear, quien hacía suyas las críticas de Quevedo: "Al Thesoro que descubrió el licenciado don Sebastián de Covarrubias Orozco, maestrescuela y canónigo de la santa iglesia de Cuenca, en alguna manera le conviene el adagio latino Thesauri Carbones. Por eso don Francisco de Quevedo Villegas, que sabía muy bien la gran extensión de nuestra lengua, dijo en su Cuento de cuentos: "también se ha hecho Tesoro de la Lengua española, donde el papel es más que la razón, obra grande y de erudición desaliñada», aunque no puede negarse que Covarrubias, siendo un hombre solo, hizo mucho" ${ }^{14}$. Y Eduardo de Mier, editor de Mayáns, anota por su parte: "El Tesoro de Covarrubias... es una obra curiosa y llena de erudición, notable a veces en la parte etimológica; pero en general absurda en su fondo, y poco filosófica y acertada en sus definiciones".

Cierto es que muchas de las etimologías propuestas por Covarrubias son totalmente equivocadas, y muchas de las noticias que proporciona, fantásticas. Pero es necesario situar el saber de Covarrubias dentro de los conocimientos propios de su tiempo. En primer lugar, conviene tener en consideración que no era la etimología disciplina muy desarrollada por aquel entonces. Covarrubias -conocedor de las lenguas latina, griega y hebrea- tenía que fundarse en la autoridad de otros humanistas cuando se tratara de voces procedentes de otros idiomas, como árabe, germánico, vascuence o indo-

bruxa); "no es mi intento divertirme de lo que en este trabajo professo, que es la etimología del vocablo" (s.v. caridad).

12 "A pesar de este propósito tantas veces repetido y de que la obra no se endereça a tratar de las materias más de lo que toca a sus etimologias y a algunas cositas que acompañen», Covarrubias muy a menudo da la impresión de redactar lo que modernamente se llama una enciclopedia, y las acositas que acompañan toman a veces proporciones desorbitadas, como por ejemplo en la palabra elefante, que viene a constituir un delicioso tratadito sobre este animal" (MARTiN de Riguer, "Prólogo" de la ed. cit,, p. vili).

13 Samuel Gili Gaya, La lexicografía académica del siglo xviii, Universidad de Oviedo, 1963, p. 11.

14 G, Mayáns y Siscar, Origenes, p. 455. 
americano. Muchos de sus errores proceden de las fuentes que estaban a su alcance. $\mathrm{Y}$ en no pocos casos, atina donde otros -inclusive décadas después- yerran. Consideremos, a manera de ejemplo, lo que revela una rápida confrontación entre lo dicho, en torno a ciertas voces, por Covarrubias y su severo censor, Mayáns y Sisear. Entre las 14 palabras de origen americano que cita Mayáns (p. 377), figuran algodón, escuerzonera, leucoma y sasafrás. No había incurrido Covarrubias en estos errores: proporciona el adecuado origen árabe de algodón; en saxifragua remite a Nebrija y en salsifrasia ofrece la etimología precisa: "Planta índica. Díxose assi quasi saxifragia, por la virtud que tiene de quebrantar las piedras de la vexiga" ${ }^{15}$; y en escorzonera se refiere al origen catalán de la planta ${ }^{16}$, relacionándola atinadamente con escuerzo 'sapo', sin alusión ninguna a América ${ }^{17}$. El intenso cultivo que de estas plantas se hacía en el Nuevo Mundo para su exportación a la Península, puede explicar que se las considerase de origen americano, al igual que sus respectivas designaciones (inclusive al algodón). Tanto la escorzonera como el sasafrás figuran entre "las cosas que se traen de nuestras Indias Occidentales, que sirven al uso de medicina" enumeradas en los tratados del Dr. Nicolás Monardes ${ }^{18}$.

No debe sorprender demasiado que Covarrubias imagine etimologías hebreas para un elevado número de palabras, inclusive para algunas amerindias, como después veremos. Aparte de su conocimiento de la lengua hebrea-que le inclinaría inconscientemente en favor de ella-, participaba de la creencia, generalizada en su tiempo, relativa a la prioridad del hebreo como lengua original, de creación divina ${ }^{19}$, y matriz de todos los demás idiomas ${ }^{20}$. De ahí

15 Cf. Juan Corominas, DCEC, s.v. saxifraga: "del lat. saxifraga, del adjetivo saxifragus 'que quiebra las piedras' (compuesto de saxum y el verbo frangere); así llamada por haberse empleado en infusión contra los cálculos de los riñones". Se refiere también Corominas a la historia del nombre de la planta americana sasafrís, que se inclina a considerar forma mozárabe.

16 Cf. Corominas, DCEC, s.v. escuerzo. Es sugerente el testimonio de F. López de Gómara (Hisloria general de las Indias, cap. 71 ; t. 1, p. 171 en la edición de Madrid, Espasa-Calpe, 1941): "Esta yerba que hay en Cartagena [de Indias] dicen que es la hipérbaton con que Alejandro sanó a Ptolomeo, y poco ha se conoció en Cataluña por industria de un esclavo moro, y la llaman escor. zonera". Acaso conoció Mayáns este pasaje, y dedujo que el nombre era de origen americano.

17 En el Tesoro de Covarrubias no figura el helenismo leucoma.

1 s Que publicó en Sevilla, en 1565 y 1571; en el primero se atiende a "la yerva escuerçonera" y a "la rays de mechoacan", y en el segundo a "la sasafras".

19 Con base en el Génesis, Covarrubias se hace eco de la general opinión: "Lo cierto y sin contradición es que la primera lengua que se habló en el mundo fue la lengua hebrea, infundida por Dios a nuestro primer padre... Duró esta lengua (sin que huviese otra) hasta después del diluvio" (Tesoro, s.v. len- 
que, siempre que fuera ello posible, los etimologistas de la época trataran de hallar raíz hebraica a todas las voces, aunque para ello tuviesen que hacer malabarismos o debiesen ignorar étimos mucho más próximos y evidentes ${ }^{21}$. Más de un siglo después de Covarrubias, todavía suponía Mayáns origen hebraico a las siguientes palabras: azote, bolsa, cofre, embajador, filateria, garguero, hulano, mesquino, pitanza, quintal, recua, saragüelles, tacaño, vaquero y zamarra (p. 362). De los 15 supuestos hebraísmos que integran la lista de Mayáns, sólo un posible acierto ${ }^{22}$, frente a 14 errores. Mucho más certero había estado Covarrubias: sólo suponía origen hebraico para azote y fulano, y vacilaba en el caso de tacaño, para el cual piensa en dos posibles étimos griegos a la vez que en el hebreo tacach 'dolo'. También vacila en el caso de zamarra, voz que supone de origen griego o hebreo, solución esta última de su preferencia. Pero, frente a estos errores, muchos más aciertos que Mayáns. Atina Covarrubias en las etimologías que proporciona para bolsa, cofre, filateria, garguero, mezquino, pitanza y vaquero, y parcialmente también en el caso de zaragüelles, cuyo origen árabe apunta como posibilidad junto a una alternativa griega y otra "bárbara" (híbrida). Y algunos de estos aciertos son verdaderamente notables. Por ejemplo, en el caso de garguero (s.v. garganta), tras relacionarlo con los términos griego y latino correspondientes, se declara partidario del origen onomatopéyico que Corominas establece hoy ${ }^{23}$ : "Yo entiendo le dio nombre el sonido que haze el gargajo quando se arranca". También es notable su acierto al relacionar pitanza, "quasi

gua). En la advertencia Al Letor precisa: "La comunicación de entre los dos [Adán y Eva] de allí adelante, fue mediante el lenguaje, no adquirido ni inventado por ellos, sino infundido del Señor... pero después del diluvio, con la confusión de lenguas, se olvidó aquélla, quedando en sola una familia, que Dios reservó a las demás, para usar de misericordia con el linage humano, haziendose hombre... los quales se llamaron hebreos y su lengua hebrea".

20 " $\mathrm{Y}$ no es de maravillar que en lenguas muy estrañas se hallen algunas palabras que tiren a las hebreas, pues desgajándose della, como de su madre, llevassen algún rastro de su primer origen" (Tesoro, s.v. lengua).

21 Quevedo, por ejemplo, deriva las voces españolas arca, mar, ala, vientre y otras, de términos hebreos (argaz, ma, halac, beten), pasando por alto la existencia de las formas latinas arca, mar, ala y venter (cf. su España defendida, cap. 4; pp. 355-356 en la ed. de Luis Astrana Marín, Madrid, 1945. Véase también, a este respecto, Raimundo Lida, Letras hispánicas, México, 1958, p. 145). Covarrubias -el por Quevedo vilipendiado Convarrubias- sí había señalado, en cambio, el origen latino de esas palabras.

22 El de tacaño, según el DCEC de Corominas. No siendo mi propósito, de ninguna manera, la discusión de etimologías dudosas o controvertidas, me atengo en este trabajo a lo que hoy en día suele darse por más probable, especialmente por parte de Corominas.

23 DCEC, s.v. gargajo: "de la raíz onomatopéyica GARG-, que imita el ruido del gargajeo y otros que se hacen con la garganta". 
pietança", con piedad (por su parte, del lat. pietas) ${ }^{24}$. Yerra, en cambio, Covarrubias en los casos de embajador (para el cual supone origen latino: de basatores < basiu) y de recua ${ }^{25}$. En total, 5 errores, 7 aciertos y 2 aciertos a medias (zaragüelles y tacaño) ${ }^{26}$; porcentaje nada desdeñable para su época. En cambio Mayáns, un siglo y cuarto después, se acredita un solo acierto (tacaño) y 14 errores. Y aún se consideraba autorizado para juzgar la obra del toledano como Thesauri Carbones.

$\mathrm{Si}$ examinamos las noticias que proporciona Covarrubias en torno a las voces de posible procedencia germánica, advertiremos que tampoco queda tan malparado como la común opinión sobre su capacidad de etimólogo haría esperar. En otro lugar he analizado el tratamiento que los germanismos reciben en el Tesoro ${ }^{27}$, compa. rándolo con el que les habían otorgado Andrés de Poza y Bernardo de Aldrete, según el estudio hecho previamente por Eugenio Coseriu ${ }^{28}$. La comparación de los resultados que obtuve en el Tesoro con los que había alcanzado Coseriu para las obras de Poza y Aldrete, sitúan a Covarrubias en una posición intermedia nada despreciable. Sobre todo, si tenemos en cuenta que el área de los germanismos no era territorio familiar para Covarrubias, desconocedor de las lenguas germánicas, en tanto que Andrés de Poza poseía un conocimiento directo del flamenco ${ }^{29} \mathrm{y}$, acaso, también del alemán ${ }^{30}$. De las 35 voces de procedencia germánica mencionadas en total por Andrés de Poza y Bernardo de Aldrete en sus listas respectivas ${ }^{31}$, Covarrubias proporciona una historia satisfactoria o, al menos, parcialmente aceptable para 19 vocablos (arnés, balcón, banquete, blanco, bosque, escanciar, ganar, ganso, jardin, rico, rocin, yelmo, arenque, boya, estafar, forrar, franco, guantes y guerra), en tanto que se equivoca en las etimologías que propone para los 16 términos res-

24 Cf. Corominas, s.t. pio: "Pitanza... contracción de pietança... sacado del lat. PIETAs".

25 "Los mulos del traginero o harriero, que llaman recuero, a requirendo, porque van buscando de una parte a otra cargas que traginar".

26 No proporciona Covarrubias etimología para quintal, pero tampoco hace alusión alguna a la procedencia hebrea supuesta por Mayáns.

27 "Sebastián de Covarrubias y el elemento germánico del español", $A L M$, 15 (1977), pp. 249-257.

28 E. Coseriu, "Un germanista vizcaino en el siglo xvi", $A L M, 13$ (1975), pp. $5-16$.

29 Poza estudió durante nueve años en la Universidad de Lovaina (cf. LA VIÑAZA, p. 17).

30 Cf. E. Coseriu, art. cit., p. 8.

3 I Por el primero, en el ya citado estudio De la antigua lengua, poblaciones y comarcas de las Españas, Bilbao, 1587. Aldrete se ocupa de este tema en el cap. 14 del lib. III de su tratado Del origen y principio de la lengua castellana, Roma, 1606. 
tantes ${ }^{32}$. Esto, utilizando el sistema estadístico o porporcional empleado por Coseriu para evaluar los aciertos de Poza y Aldrete, representa un $54.3 \%$ de éxito para nuestro autor, que lo sitúa a medio camino entre sus precursores: Poza alcanza un $66.6 \%$ de aciertos, y Aldrete sólo un $48.7 \%$.

Los instrumentos con que debían laborar los etimólogos de aquel tiempo eran todavía sumamente rudimentarios. Covarrubias parece advertirlo, y de ahí que, en muchas ocasiones, se limite a consignar las diversas explicaciones etimológicas propuestas por distintos autores para cada voz, sin tomar partido por ninguna de ellas ${ }^{33}$. En otros casos, declara su personal preferencia, a veces equivocada, en especial por su inclinación en favor de cualquier hipótesis hebraizante $^{34}$. Y en no pocas ocasiones, por último, proporciona explicaciones un tanto ingenuas, deslumhrado por falsas similitudes formales de ciertas palabras ${ }^{35}$. Pero no es posible regatear elogios al esfuerzo enciclopédico hecho por el toledano. El número y variedad de sus fuentes bibliográficas es notable. Sólo en relación con las voces de posible origen germánico, menciona a San Isidoro, a Antonio de Nebrija, a Francisco Sánchez de las Brozas, al P. Juan de Mariana, al P. Juan de Pineda, a Martín del Río, así como a los arabistas Diego de Urrea, Francisco López Tamarid y el P. Diego de Guadix, además de sus precursores Andrés de Poza y Bernardo de Aldrete; esto sólo en cuanto a los españoles. Autoridades extranjeras son para Covarrubias, en ese reducido campo, Ambrosio Calepino, Francesco Alunno de Ferrara, Carolo Bobillio (Charles

32 Para albergar, arpa, bala, baluarte, bandera, bando, bordar, escaramuza, escote, esgrimir, estandarte, flota, guardar, mästil, raspar y rueca.

33 Cf., por ejemplo, lo que escribe s.v. cama: "Danle diversas etimologias: referirélas todas, y cada uno escogerá la que mejor le pareciere".

34 Aunque no siempre se deja engañar por este espejismo: al estudiar el origen de la palabra rico, afirma sin vacilación que es "nombre godo", no obstante que conocía la hipótesis referente a una posible procedencia hebraica: "Algunos quieren dezir que este bocablo rico es hebreo, de la palabra rich, vanitas".

35 Aunque tampoco peca de ingenuidad en todos los casos. Atinadamente cauto se muestra al analizar el origen de algunas voces de aparente estructura fonética árabe. Así, en el caso de azúcar, explica: "Este vocablo es bien conocido, pero la gente vulgar piensa ser arábigo, por tener el artículo $a$. Pero es cierto que los árabes tomaron de la lengua latina y de la griega muchas dicciones, y las hizieron propias; y una de ellas es açucar, de $a$, artículo lunar, y saccharum, nombre griego $\sigma \alpha x \alpha$ pov". Idéntica prudencia en el caso de alam. bre: "Este vocablo está corrompido, porque hemos de dezir arambre, y no alambre; de donde constará no ser arábigo, como algunos piensan, sino latino, de aes, aeris, aerambre... Los que entienden ser arábido alambre, dizen estar compuesto de al-yambre, que llamamos ámbar, por tener aquella color". Un ejemplo más: "Açufre. Este nombre parece arábigo, por razón del artículo, pero notoriamente está corrompido de la palabra latina sulphur". 
de Bouelles), Angelo Rocca, Andrea Bacci, Juan Goropio Becano (Jan van Gorp) y Abraham Ortelius, sin contar a los clásicos grecolatinos -entre los cuales Plinio es el más utilizado- y las incuestionables fuentes bíblicas.

Si la historia de las lenguas europeas se hallaba todavía en su etapa precientífica, ¿qué podremos esperar que se supiera, en aquel entonces, en torno a las lenguas americanas? Cuando Covarrubias preparaba su diccionario, algunos de los más importantes idiomas amerindios habían sido ya estudiados y codificados por aquellos admirables misioneros convertidos en gramáticos -excelentes gramáticos- por la fuerza de las circunstancias. La lengua náhuatl, en especial, estudiada inicialmente por fray Andrés de Olmos, había recibido la esmerada atención de fray Alonso de Molina, cuyo Vocabulario se imprimió en México en $1555^{36}$. El léxico tarasco había sido ordenado por fray Maturino Gilberti y, poco después, por fray Juan Bautista de Lagunas ${ }^{37}$. Fray Juan de Córdoba había impreso ya su Vocabulario en lengua zapoteca (México, 1578), y fray Francisco de Alvarado el suyo sobre la lengua mixteca (1593). La "lengua general del Perú, llamada quichua" había sido codificada por fray Domingo de Santo Tomás (Valladolid, 1560) y por el P. Diego González de Holguín (Lima, 1608). Sin embargo, estas obras -destinadas fundamentalmente a los misioneros empeñados en la evangelización del Nuevo Mundo- no alcanzaron mucha difusión en Europa por aquel entonces. Es muy probable que Covarrubias no tuviera noticia de ninguna de ellas. Al menos, a ninguna alude en las entradas que dedica a las voces de origen americano en su $T e$ soro. Las noticias que sobre esos términos llegó a reunir procederían de fuentes histórico-literarias. Aproximémonos a esos vocablos amerindios.

La lista total de los indoamericanismos que he logrado encontrar en el diccionario de Covarrubias es la siguiente: acal, Araucana, cacique, caimán, canoa, coca, Cuzco, hamaca, huracán, inga, maiz, mechoacán, mexicano, México, mico, Motezuma, nopal, Perú, perulero, pita, Tenochtitlan, tiburón y tuna. Veintitrés voces en total.

Cabe suponer que Covarrubias diera entrada en su Tesoro únicamente a las palabras que hubiesen adquirido ya carta de naturaleza en la norma lingüística española, pero no a términos que -aunque conocidos en la Península - se sintieran como exóticos o peculiares del mundo americano. De acuerdo con esta suposición, sor-

$36 \mathrm{La}$ parte correspondiente al vocabulario mexicano-castellano se publicó en 1571 .

37 Aludo al Vocabulario en lengua de Mechuacán (México, 1559) de Gilberti, y al Arte y Dictionario en lengua Michuacana (México, 1574) del P. Lagunas. 
prende la presencia, en su diccionario, de acal y de Tenochtitlán, y en cambio se echan de menos algunas voces que acaso fueran ya usuales en el vocabulario peninsular, como cacao, naguas y batata. Lo primero tiene fácil explicación: ni acal ni Tenochtitlán poseen entrada propia en el Tesoro, sino que aparecen indirectamente: Hablando de las canoas, dice Covarrubias que "en lengua mexicana... llaman a estas varquillas... atlcales, que vale tanto como casas de agua, porque en algunas partes viven en ellas dentro de las lagunas, por assegurarse de enemigos y de fieras de la tierra". Asimismo, al hablar de la ciudad de México, dice que "el propio nombre suyo fue Tenuchtitlan", y proporciona luego su etimología.

Más difícil resulta explicar la ausencia de algunos indoamericanismos posiblemente ya generalizados en el habla castellana. Cervantes emplea -además de caimán y huracán, también recogidos en el Tesoro- los americanismos bejuco, cacao y caribe ${ }^{38}$. El primero no debió de hacerse muy usual nunca, por tratarse de una realidad extraña a la naturaleza castellana: figura, sin embargo, en el Dictionarie in Spanish and English (London, 1599) de Richard Percyval y en los posteriores de Jean Palet y César Oudin ${ }^{39}$, así como en el muy posterior (1693) e inédito Tesoro de la lengua castellana de Juan F. de Ayala Manrique, s.v. bejunquillo ${ }^{40}$. También quedó consignado en el Diccionario de Autoridades, con referencia única al pasaje del Persiles en que Cervantes lo había empleado. Tal vez fuera más usual el americanismo cacao, por cuanto que Cervantes se sirve de él dentro de una frase hecha: "no estimar en un cacao" ${ }^{41}$. Caribe, por último, debía de ser voz exótica: Cervantes la usa dentro de una enumeración un tanto cultista ${ }^{42}$, y no figura en ningún diccionario anterior al de Covarrubias ${ }^{43}$. Parece lógico que éste no lo consignara en un vocabulario que trataba de reunir las voces propias de la lengua castellana y verdaderamente usuales en ella.

38 Cf. Carlos Fernández Cómez, rocabulario de Ceriantes, Real Academia Española, Madrid, 1962.

39 Cf. JEan Pallet, Diccionario muy copioso de la lengua española y francesa, París, I604; CÉsAR Oudin, Tesoro de las dos lenguas francesa y española, Paris, 1607. Me sirvo de las noticias reunidas por Samuel Gili Gaya en su Tesoro lexicográfico (1492-1726), t. I (A-G), Madrid, 1947.

40 "Hierua que viene de Indias y usan los médicos por vomitorio. También se llaman assi las cadenillas muy delgadas de oro".

41 "Que el mosqueo de las espaldas, ni el apalear el agua en las galeras, no lo estimamos en vn cacao" (La Gitanilla). Figura en el Tesoro de Oudin (1607), de donde pasó al diccionario de Girolamo Vittori (1609), y a otros posteriores.

42 "Fuera yo vn Polifemo, vn Antropófago, vn Troglodita, vn bárbaro Zoylo, vn Caymán, vn Caribe" (El rufián viudo).

43 Por primera vez aparece en el Vocabularium hispanicum latinum et anglicum de John Minsheu, Londini, 1617. 
De no haber sido éste su criterio de selección, resultaría descuido excesivo el no haber dado entrada en su obra a voces que -como cacao, caribe o bejuco- habían sido ya ampliamente explicadas en escritos sobre América que Covarrubias conocía muy bien ${ }^{44}$. De ahí, precisamente, el interés del Tesoro para precisar el grado de vitalidad alcanzado, en el habla castellana, por los indoamericanismos al rayar el siglo xvn. Cierto es que algunas voces amerindias se documentan en diccionarios anteriores al de Covarrubias. En el Tesoro lexicográfico preparado por Gili Gaya figuran las siguientes, que no hallan lugar en la obra de Covarrubias: arcabuco, axi, batata, bexuco, bohio, cacao, caimito, caoba, caribe, cazabe, cocuyo y chile. Salvo cacao y, sobre todo, batata ${ }^{45}$, no creo que ninguna otra tuviera verdadera vitalidad a comienzos del siglo xvn en el español peninsular. Morínigo enumera otros americanismos más, no registrados por Covarrubias, como usuales en ese siglo ${ }^{46}$ : chocolate. naguas, jicara, jalapa, tomate, vicuña y patata. Pero cabe preguntarse si estas palabras serían verdaderamente usuales en la España de comienzos del siglo xvn. Por supuesto que jalapa no, ni llegó a serlo nunca; además de que las fechas de sus más antiguas documentaciones son posteriores a la del Tesoro de Covarrubias: como rayz de Xalapa, en 1615, y como xalapa a secas, en 1721 (cf. Corominas,

44 Del cacao hablan extensa y reiteradamente López de Gómara (por ejemplo, en Historia general, caps. 205 y 208, y en Conquista de México a cada paso) y el P. José de Acosta (Historia natural y moral de las Indias, lib. IV, cap. 22). Asimismo de los caribes, que "comen carne humana, fresca y cocinada", y de los bejucos, tan usados por los propios conquistadores para hacer balsas, a falta de "clavazón" (Gómara, Méx., II, p. 126 de la ed. de Barcelona, 1887)

45 Batata aparece en el Guzmán de Alfarache y, por primera vez en obras lexicográficas, en el Tesoro de Vittori (1609). El cultivo de la batata se había iniciado con éxito en España antes de que Covarrubias publicara su Tesoro. Abundan los testimonios: "Algunos de estos [géneros de raíces] se han traído a Europa, como son batatas, y se comen por cosa de buen gusto" (P. JOSEPH DE Acosta. Historia natural, lib. IV, cap. 18; p. 173 en la ed. de Edmundo O'Gorman, México, 1962); "alas raizes que de alia vinieron no vistas ni conocidas antes en Europa, dezimos patatas" (por batatas: AldreTe, Origen, p. 111); "las que los españoles llaman batatas, y los indios del Perú apichu... las menos buenas son las que han traído a España" (InCA Garcilaso, Comentarios reales, lib. VIII, cap. 10) ; "las batatas, a todos muy conocidas" (AnTonio dE Herrera, Historia general de los hechos de los castellanos, Década I, lib. X, cap. 9) . Y López de Gómara, principal fuente informativa americana para Covarrubias -como pronto veremos--, menciona y describe reiteradamente las batatas en su Historia general de las Indias. Acaso sea ésta la principal omisión, dentro del marco indoamericar:o, del Tesoro de Covarrubias.

46 Marcos A. Morínigo, "La penetración de los indigenismos americanos en el español", en Presente y futuro de la lengua española, t. 2, Madrid, 1964, pp. 217-226; cf. p. 220. 
DCLC). Tampoco vicuña, como nombre de una realidad ajena a la vida española, podía ser voz popular o usual. La introducción del chocolate en los hábitos alimenticios de los españoles debió de ser bastante tardía: todavía en 1615 , el P. Francisco Jiménez describe el proceso de su preparación como actividad exótica -que requería de una explicación- propia de los mexicanos ${ }^{47}$; además la primera documentación de la palabra es tardía - de hacia 1580 - y presenta aún una estructura fonética náhuatl, no castellana: chocollatl ${ }^{48}$; $y$, por último, la primera vez que aparece consignada en uno de los diccionarios renacentistas europeos es en fecha ya avanzada -en el de Oudin de 1616- y como realidad exótica: "Certain breuage noir que les Americains font auec un fruict nominé cacao". Nada de extraño tiene, por lo tanto, que Covarrubias no la recogiera en su $T e$ soro. Lo mismo cabe decir de la palabra tomate, si consideramos que todavía Fr. Alonso de Molina, en 1571 y en México, la sentía como voz propiamente indígena ${ }^{49}$ : "Tomatl, cierta fruta que sirue de agraz en los guisados o salsas". En lo que respecta a patata, no es posible olvidar que "hasta el s. xvir la patata fue vegetal muy poco conocido en España (como todavía revela la vaga y extraña definición de $A u t$.) ${ }^{50}$, y hasta entonces no se le dio otro nombre que papa" (Corominas), contra lo consignado por Morínigo; en efecto, las primeras apariciones literarias de la voz patata hacen referencia, muy probablemente, a la batata ${ }^{51}$. De todas esas palabras, por lo tanto, sólo dos - (e)naguas y jicara- serían tal vez usuales en España a co-

47 Cf. Cecilio A. Robelo, Diccionario de aztequismos, 3a ed., México, pp. 314-315.

48 En la Historia natural de la Nueva España de Francisco Hernández, obra altamente especializada; como chocolate, también hacia 1581 (cf. P. BoyD-BowMAN, Léxico hispanoamericano del siglo xvi, London, 1971; es su única documentación en ese siglo). La forma chocolate no figura aún en el diccionario de Fr. Alonso de Molina (cf. Corominas, DCEC). También la descripción del P. Acosta (1590) prueba que se trataba de algo ajeno a la vida española: "EI principal beneficio de este cacao es un brebaje que hacen que llaman chocolate, que es cosa loca lo que en aquella tierra le precian, y algunos que no están hechos a él les hace asco; porque tiene una espuma arriba y un borbollón como de heces, que cierto es menester mucho crédito para pasar con ello" (Historia, lib. IV, cap. 22) .

49 La recoge en el vocabulario mexicano-castellano, pero naturalmente que no en el castellano-mexicano (cf. además Coromịas, DCEC).

50 "Ciertas raices que se crian debaxo de la tierra, sin hojas y sin tallo, pardas por de fuera y blancas por de dentro. Es comida insípida" (Diccionario de Autoridades). Y los dos testimonios documentales que cita ahí la Academia se refieren precisamente a América.

51 Todavía en 1737, Mayáns y Siscar habla de la patata como "la raíz dulce tan conocida de todos después que en Málaga ha probado tan bien, y me persuado que en mi patria Oliva probaría mejor, siendo tan excelentes sus cañas dulces" (Origenes, p. 379). 
mienzos del siglo xvn. La primera, documentada desde muy temprano, fue usada por Lope de Vega, Tirso de Molina y Calderón de la Barca; la segunda, también por Lope y Tirso ${ }^{52}$, y además por Moreto. El hecho -antes anotado- de que algunos de los indoamericanismos que figuran en el Tesoro de Covarrubias no aparezcan con entrada propia (acal y mexicano se consignan en el texto correspondiente a la entrada canoa; nopal y Tenochtitlan, s.y. México) es prueba del criterio de selección empleado por nuestro lexicógrafo: ni nopal ni acal, ni mucho menos Tenochtitlan, eran voces arraigadas en la lengua española; nopal está ausente todavía en el Diccionario de Autoridades. Lo que sí sorprende, a este respecto, es que Covarrubias diera cabida en su diccionario, reservándole entrada propia, al término mechuaeán, que no debía de ser más conocido que otros muchos de los que desecha.

La casi totalidad de los 23 indigenismos americanos reunidos por Covarrubias quedan explicados como designaciones correspondientes a realidades del Nuevo Mundo. Sólo dos se describen sin vincularlos expresamente con América: coca y maiz. En lo que respecta al primero, Covarrubias sólo dice que es "cierta droga, que se llama coca o coco de Levante, con que suelen los pescadores emborrachar al pescado y hazer que ande adormecido sobre el agua"; queda la duda -expresada por Corominas- sobre si esta droga "debe su nombre, según es verosímil, a la coca peruana, por el efecto tóxico de ésta, o si es denominación culta, alterada en lugar de coco de Levante... procedente de xóxxos 'grana, pepita'". En la edición de 1616 del Tesoro de César Oudin - de donde pasó a la del vocabulario de Minsheu de 1617-, coca designa la "herbe du Perou" usada por los indígenas como estimulante; en cambio Franciosini, en 1620, recoge la descripción hecha por Covarrubias, sin relación expresa con el Nuevo Mundo, cosa que no deja de sorprender, ya que el origen americano de la planta y de su nombre consta profusamente en los historiadores de Indias, algunos de los cuales fueron consultados por Covarrubias ${ }^{53}$. Mucho más sorprende que tampoco el maiz quede expresamente vinculado con América. Todo lo que sobre él dice Covarrubias es lo siguiente: "Suerte de panizo que haze unas mazorcas, y en ellas unos granos amarillos o roxos, tamaños

52 Verdad es que Tirso de Molina -sin duda para proporcionar colorido americano a las comedias que lo requerían- se sirvió de indoamericanismos que probablemente desconocían sus contemporáneos, como curaca, jaojao, carey, jején, anacona y otros más (cf. Manuel García Blanco, "Voces americanas en el teatro de Tirso de Molina", BICC, 5, 1949, pp. 264-283) .

53 De la coca hablan, con bastante amplitud, López de Gómara, Historia, cap. 193; P. Cieza de León, Crónica del Perú, cap. 96; P. Acosta, Historia natural, lib. IV, cap. 22; Inca Garcilaso, Comentarios reales, lib. VIII, cap. 15. 
como garvanços, de los quales molidos haze pan la ínfima gente" ${ }^{\mathbf{5 4}}$. Cabe suponer que Covarrubias olvidara, simplemente, señalar el origen americano de la planta y de su nombre, o que lo diera por bien sabido; pero cabría también imaginar que estuvieran ya tan arraigadas en España tanto la planta como su designación, que Covarrubias mismo hubiera olvidado su origen ultramarino ${ }^{55}$.

Los 21 términos restantes sí quedan adecuadamente vinculados con el mundo americano. De cacique dice Covarrubias que "vale tanto, en lengua mexicana (!), como señor de vassallos". Caimán es "un pez lagarto que se cría en las rías de Indias". Canoa "es vareo hecho ordinariamente de una pieça como artesa, de que usan los indios". Cuzco y Araucana se definen como "provincia de las Indias Occidentales". Al hablar de los ingas dice que "deste nombre se llamaron los reyes del Perú, de uno de ellos el más antiguo". Nopal aparece como una realidad mexicana. Pita es una "yerva de Indias, de la qual hazen un hilo muy delicado para guarniciones, como acá se saca el hilo del cáñamo y del lino" ${ }^{56}$. El tiburón se define como "un pescado grande que sigue las naves que van a Indias". Y la tuna, finalmente, "es una especie de higuera de las Indias". Sólo la procedencia americana del mico queda imprecisa: "yo sospecho ser nombre impuesto en la mesma patria de adonde primero lo truxeron".

Analicemos, por último, las etimologías que para estos indoamericanismos propone Covarrubias. En realidad sólo se arriesga a sugerir étimos concretos para doce vocablos; para los restantes se limita a consignar su raigambre americana, pero sin proporcionar etimologías precisas. Su cautelosa actitud queda reflejada en lo que dice al hablar del caimán: "por ser el nombre de aquella lengua bárbara, no me han sabido dar su etimología" ${ }^{5 \tau}$. Los términos para los que Covarrubias propone alguna etimología concreta son: acal, Araucana, cacique, hamaca, huracán, mechoacán, México y mexicano, Mo-

54 Definición que - como en el caso de otros muchos conceptos- fue recogida por la Academia: "Cicrta especie de panizo, que produce unos tallos altos, y en ellos echa unas mazorcas llenas de granos amarillos o roxos, redondos y más pequeños que garbanzos: de los quales molidos se suele hacer pan. Lat. Millium Indicum".

55. A pesar de que consta reiteradamente en todas las crónicas sobre América. Que Covarrubias hubiese llegado a olvidar el origen americano del maiz lo permite imaginar el hecho de que, tras definirlo, remita a Plinio, identificando el maíz con el milium indicum, como haría también posteriormente la Academia (cf. nota anterior).

56 No es, pues, Antonio de Herrera -como indica Corominas- el único autor antiguo que emplea pila como nombre de la planta, y no del hilo o fibra. La usó también, en esa acepción, Constantino Bravo de Lagunas: "ay un genero de yeruas que llaman pita a manera de hoja de lirio" (Relación de Xa lapa, 1580; ed. de L. Pasquel, México, 1969, p. 38).

sт Cf. también lo dicho antes en relación con el mico. 
tezuma, Perú, perulero y Tenochtitlan. Y aqui, de nuevo, vuelve nuestro autor a cojear del mismo pie que tantas veces le hace tropezar a lo largo de la obra: su inclinación a buscar raices hebraicas siempre que ello le parece posible. Cojea así, en efecto, cuando explica el origen de cacique, hamaca y Araucana, y al menos parcialmente en lo que respecta a Perú. Cierto es que -salvo en el caso de Araucana- no propone las respectivas etimologías hebreas como cosa cierta, sino sólo como posibilidad más o menos remota, o como hipótesis de "otros" autores. Para mejor comprender la actitud científica de Covarrubias, conviene meditar en lo que dice al explicar la voz cacique: "Vale tanto... como señor de vassallos, y entre los bárbaros aquél es señor que tiene más fuerças para sujetar a los demás. Y presupuesto que los que poblaron el mundo después del diluvio, dividiéndose en la confusión de las lenguas al fabricar la torre de Babel o Babilonia, cada nación de las que se apartaron llevaron consigo algún rastro de la lengua primera, en la qual avían todos hablado, y quedó con Heber y su familia, de donde procedieron los hebreos; y assi digo que este nombre cazique puede traer origen del verbo hebreo chazach 'roborare', y de allí chezech 'fortitudo et fortis', de donde se pudo dezir cazique; con todo esso yo me remito a los que tienen noticia de la lengua"... americana, se entiende. Y claro está que, partiendo de ese axioma bíblico, también hamaca -aun siendo "cama de indios" y realidad de origen y utilización exclusivamente americana- "puede ser nombre hebreo, del verbo hhamak 'vertere, convertere', porque se buelven y rebuelven en ella". De igual manera, el nombre de la Araucana -en vez de Arauco"vale tanto como ardiente, seca, calurosa, del verbo hebreo arau, vel harau 'avescere, siccari, confici" ". En lo que se refiere al nombre del Perú, se hace eco Covarrubias de dos hipótesis: una que supone origen autóctono a la palabra -de la que después hablaremos- y que parece ser la preferida del lexicógrafo, y otra que le concede base hebraica, y que Covarrubias no se anima a respaldar: "Otros quieren -dice- que sea nombre hebreo, quasi pere, del verbo parad 'partiri, dividere, separare', por ser tierra tan apartada y dividida de las demás".

Tampoco acierta Covarrubias al proponer la etimologia de huracán. En dos lugares de su obra aparece consignada esta palabra, con entrada independiente: s.v. huracán (p. 706a) y s.v. uracán (p. $987 b$ ). En la primera entrada no se alude siquiera a su relación con la empresa de América, omisión que queda subsanada en la segunda, donde se explica: "Un cierto viento que en la carrera de las Indias suele echar a fondo los navios, trayéndolos a la redonda" 58 .

58 Explicación muy semejante a la proporcionada s.\%. huracán: "Un viento que va haziendo un remolino, con el qual trayendo los navios a la redonda 
Llama la atención el hecho de que en cada entrada proporcione Covarrubias diferente etimología al término huracán. En la primera, lo hace derivar del verbo horadar, dado que "trayendo los navios a la redonda los hunde, que parece horadar con ellos el agua; y assí se dixo horacán" ${ }^{59}$. En la segunda arriesga, no una, sino dos hipótesis, la primera de las cuales es verdaderamente maravillosa: podría llamarse uracán porque "suele echar a fondo los navios trayéndolos a la redonda y uracando el mar para que se los trague: uraco es término sayagués, y vale agujero, y de allí uracar, agujerear" "00. Menos imaginativa resulta la segunda hipótesis: "podría ser griego oupos, latine impetus".

Mejor suerte corren, en cambio, los americanismos acal, Tenochtitlan, México (y mexicano), mechoacán, Motezuma y, en cierta medida, Perú. Notable es lo que dice en torno a los dos primeros: los indios "llaman a estas varquillas en su lengua atlcales, que vale tanto como casas de agua, porque en algunas partes viven en ellas dentro de las lagunas, por assegurarse de enemigos y fieras de la tierra. Es nombre compuesto de atl, que vale agua, y calli, casa, y todo junto casas de agua ${ }^{61}$. Esto es en lengua mexicana; mas porque las tales varquillas las llaman en Santo Domingo, donde primero estuvieron los españoles, canoas, las llamaron a todas deste nombre" (Tesoro, s.v. canoa). Sorprende asimismo por su precisión lo oue explica sobre la ciudad de México: "El propio nombre suyo fue Tenuchtitlan, compuesto de nuchtli ${ }^{62}$, que vale la fruta de la tuna, y de tetl, que es piedra, porque quando se començó a poblạr México fue cerca de una piedra que estava dentro de la laguna, de la qual nacía un nopal o tuna muy grande; y por esto tiene México por armas y divisa un pie de nopal nacido entre una piedra, conforme a su nombre". En cuanto al nombre México, tampoco anda tan desatinado como en los casos anteriores: "Algunos quieren que se aya dicho de los primeros que allí la fundaron, que se dixeron mexit $i$ " 63 .

los hunde". Pero aquí añade algo oue faita s.v. uracán: "Este mesmo suele correr en la tierra. y arranca los árboles y derrueca los edificios".

59 No resulta, por cierto, mucho más feliz la etimología que propuso la Real Academia un siglo largo después: "En latín le llaman Ventus furens, de donde se pudo decir Furacán, y corrompido Huracán” (Dicc. Aut.).

60 Martín de Riquer puntúa e interpreta equivocadamente: ". . y de alli uracar; agujerear podría ser griego".

61 Etimología absolutamente exacta: cf, Robelo, Dicc., p. 11.

62 En la edición de Riquer, nuchth, sin duda mala lectura de -li (cf. infra).

63 No es, en realidad, importante para los fines de este trabajo el hecho de que hoy se propongan otras etimologias para Tenochtitlan; como la de C. A. Robelo, para quien significa "lugar fundado bajo (titlan) el mando o gobierno de Tenoch" (Nombres geográficos indigenas del Estado de México, Cuernavaca, $1900 ;$ p. 14), interpretación que hace suya José I. DÁvild Garibi (Topo- 
Aunque no consigne el étimo nahua preciso, también otorga Covarrubias un atinado origen americano y sugiere una adecuada explicación etimológica amerindia tanto para mechoacán como para Motezuma. De la primera dice: "Una raíz medicinal, que en nuestros tiempos se ha traydo de las Indias; dicha así de la provincia de donde se trae, la qual se llama la provincia de Mechoacán"; y, en cuanto a su etimología, explica que "vale mechoacán tanto como lugar de pescado, porque en aquella provincia ay muchas lagunas, con abundancia de pesca" 64. En lo que respecta a Motezuma, escribe: "Nombre de aquel potentíssimo rey indio; vale tanto como hombre sañudo y grave" 65. Y añade a continuación un curioso y acertado comentario: "Los indios le llamavan Motezumacin: el cin vale tanto como cerca de nosotros el don, y sólo le ponían al cabo del nombre del rey o gran señor" ${ }^{66}$.

No me ha sido nada difícil determinar de dónde tomó Covarrubias informaciones tan precisas: atendiendo a la autoridad que suele conceder a los historiadores (por ejemplo, al P. Mariana en el caso de los germanismos), cabía pensar que todos esos datos tan concretos procedieran de algún cronista de Indias. Y entre ellos, uno de los más leídos en su tiempo fue López de Gómara. En su Conquista de México, en efecto, aparecen todas esas explicaciones, casi con las mismas palabras que utilizaría después Covarrubias. Compárese lo que dice López de Gómara en torno a las canoas con lo antes transcrito de Covarrubias: “. . . barquillas que los naturales llaman acalles, que quiere decir casas de agua; porque atl es agua, y calli, casa, de que está el vocablo compuesto. Los españoles las dicen canoas, avezados a la lengua de Cuba y Santo Domingo" 67 . La misma coincidencia se advierte en el caso de Tenochtitlan. La explicación de Gómara es la que repetiría Coyarrubias: "su propio y antiguo nom-

nimias nahuas, México, 1942, pp. 58 y 61). Para Mexictli como étimo de México, cf. Robelo, Dicc., pp. 87 y 89.

64 "De michi, pescado, se forma michhuah, pescador, luego Micchhuácan, dice tanto como región de pescadores" (J. I. Dávila Garibi, Toponimias, p. 28; cf. también p. 221).

65 Motecuhzoma en su forma nahua etimológica (cf. J. I. DÁvila Garibi, Algunas analogias fonéticas, México, 1954, p. 22). Compuesto de Mo-teuc-zoma, literalmente 'mismo-señor-enojar' (Madricio Swadesh y Madalena Sancho, Los mil elementos del mexicano clásico, México, UNAM, 1966, p. 24).

66 En efecto, como bien se sabe, -tzin [śin] es sufijo reverencial del náhuatl (cf. Ángel M. Garibay, Llave del náhuatl, 2a ed., México, 1961, pp. 54-55).

67 Cap. 78, p. 184, t. 1, de la ed. de Barcelona, 1887. Corrobora esta dependencia un pormenor relativo al número de tales barquillas: López de Gómara dice que "en sólo México hay ordinariamente cincuenta mil de ellas para acarrear bastimentos y portear gente"; y Covarrubias repite: "Los nuestros afirman aver en solo México más de cinquenta mil dellas, con que portean gentes y traen bastimentos". 
bre es Tenuchtitlan, que significa fruta de piedra; ca está compuesto de $t e t l$, que es piedra, y de nuchtli, que es la fruta que en Cuba y Haití llaman tunas" (p. 181) ${ }^{68}$. Idéntica dependencia en el caso de México. Escribe López de Gómara: “También afirman otros que se llamó México de los primeros fundadores, que se dijeron mexiti; que aún ahora se nombran mexica los de aquel barrio y población". De igual manera, lo que Gómara había dicho sobre el significado de los nombres Michoacán y Moctezuma es lo que repetiría Covarrubias. Del primero, escribe el cronista: "Sin esta laguna, hay en aquel reino otros muchos lagos, en que hay grandes pesquerías; a cuya causa se llama Michuacán, que quiere decir lugar de pescado" (cap. 148, p. 66 del tomo 2 de la ed. citada) ${ }^{69}$. Covarrubias añadió la noticia sobre la raíz medicinal del mismo nombre, dato que tomó del Dr. Nicolás Monardes, según él mismo declara (cf. nota 18). Del emperador azteca dice López de Gómara: "Motezuma quiere decir hombre sañudo y grave". También la explicación sobre el valor reverencial del sufijo -cin aparece en Gómara: "A' los nombres propios de reyes, de señores y mujeres, añaden esta sílaba cin, que es por cortesía o dignidad, como nosotros el don, turcos sultán, y moros mulei" 70 .

Cabe preguntarse por qué no citaría Covarrubias a López de Gómara al presentar sus etimologías mexicanistas. No creo que fuera por el deseo de adornarse con plumas ajenas, práctica que no parece ser muy propia de su temperamento ${ }^{71}$. Por otra parte, hay que

$68 \mathrm{Y}$ en la página siguiente da Gómara la explicación que también tuvo eco en el Tesoro de Covarrubias: "cuando se comenzó a poblar [la ciudad de México] fue cerca de una piedra que estaba dentro de la laguna, de la cual nacia un nopal muy grande, y por eso tiene México por armas y divisa un pie de nopal nacido entre una piedra, que es muy conforme al nombre".

69 Esta noticia, como tantas otras de su crónica, pudo tomarla Gómara de fray Toribio de Benavente, Motolinia, en cuyos Memoriales explica: "Hay en esta región de Michuacan grandes estanques y lagos... y en ellos hay mucho pescado y bueno; por lo cual la etimología e interpretación de su nombre le conviene muy bien y es conforme a su propiedad, como lo son todos los nombres de esta lengua, porque Michuacan tanto quiere decir como lugar de mucho pescado" (p. 280 en la ed. de Edmundo O'Gorman, UNAM, México, 1971). Lo mismo cabe decir sobre las etimologías de Tenochtitlan y México, que Mo. tolinia explica en la p. 204 de sus Memoriales de igual manera que lo haria después López de Gómara.

70 Cap. 67, p. 164. Tomado también de Motolinia, quien había escrito: "Moteczuma quiere decir hombre triste y sañudo... que ei buena significación quiere decir hombre grave y modesto" (p. 9 de la ed. cit.). Y allí mismo, la explicación del sufijo tzin: "Aquesta dicción cin que se añade a los nombres de los señores aquí nombrados, no es propia de los nombres, mas añádese por cortesía y dignidad y acatamiento".

71 Muy por lo contrario, Covarrubias cita reiteradamente a los autores a 
señalar que sí menciona al cronista de México en la entrada correspondiente a tiburón, voz para la cual no proporciona etimología alguna, posiblemente por no encontrar sentido a la explicación de López de Gómara ${ }^{72}$.

En lo que respecta al topónimo Perú, ya hemos visto cómo se limita Covarrubias a consignar la hipótesis relativa a un posible origen hebraico, aunque previamente antepone una explicación indigenista, muy difundida ya en su tiempo: "Algunos dizen y afirman por cierto averse dicho Perú de un río que corre por aquella provincia, llamado Perú". Y a continuación, hace una referencia bibliográfica que origina un nuevo problema: "El padre Josefo de Acosta, en el Libro de natura novi orbis, lib. I, caps. 13 y 14, refiere aver sido puesto a caso, conviene a saber, en esta manera: que llegando españoles a aquella provincia toparon a un indio y, preguntándole qué tierra era aquélla, respondió Berú Pelú, que ni él supo lo que le preguntaron, ni ellos entendieron lo que les respondió. Pero de aquí conjeturaron que se llamara Perú, y assi le pusieron este nombre". El problema radica en que esta última explicación no figura en la Historia natural del P. Acosta ${ }^{73}$; en cambio, sí aparece la más escueta citada en primer lugar, que Covarrubias atribuye a "algunos" autores indeterminados. El P. Acosta había escrito: "Acá es opinión que de un río en que a los principios dieron los españoles, llamado por los naturales Pirú, intitularon toda esta tierra Pirú; y es argumento de esto que los indios naturales del Pirú ni usan ni saben tal nombre de su tierra" 74 . Estas imprecisiones -0 , más bien, errores- en las referencias hechas por Covarrubias inclinan a pensar que - caso de no haber revuelto sus propias anotaciones, cosa posible - no fue al P. Acosta a quien debía la información, sino a algún otro autor. Me atrevo a pensar que su verdadera fuente bibliográfica fue el tratado Del origen y principio de la lengua castellana de Aldrete, que -como ya apuntamos- conocía y utilizó Covarrubias. En efecto, en el cap. 13 del libro III de ese tratado, recoge Aldrete, en forma sucinta, la explicación dada por el Inca Gar-

quienes concede verdadera autoridad, como al P. Guadix, a Diego de Urrea y a López Tamarid en lo que a los arabismos toca.

72 Quien escribe: "el tiburón es tragón, que por eso algunos le llaman ligurón" (cap. 16, p. 42). Cf. lat. ligurire 'comer con ansia', en Horacio.

73 Cuyos dos primeros capítulos son la traducción, hecha por el propio P. Acosta ya de regreso en España, del tratado De natura novi orbis escrito durante su permanencia en el Perú y publicado en Salamanca un año antes que la Historia, según él mismo declara tanto en el "Proemio al lector" puesto al frente de la Historia natural, como en la "Advertencia al lector" que encabeza el libro III, redactado ya en la Península.

74 P. JosepH de Acosta, Historia natural, lib. I, cap. 13 (p. 40 en la ed. citada). 
cilaso de la Vega. Las palabras empleadas por Aldrete son muy próximas a las que usaría Covarrubias: "El nombre del Perù no fue antiguo, sino puesto mui a caso. Quando los Españoles llegaron aquellas partes, a vn Indio, que cogieron, preguntaron que tierra era aquella, el sin entender lo que le dezían, respondió Beru Pelu, de lo qual ellos coligieron que era el nombre de la tierra, con que le dixeron Perù'. En nota marginal, agradece Aldrete esta información al Inca Garcilaso, cuyos Comentarios reales -donde la anécdota aparece con amplio detalle - no habían sido publicados todavía ${ }^{75}$. Creo que Covarrubias revolvió sus papeletas, y atribuyó al P. Acosta lo que tomaba de Aldrete y, en cambio, lo que tomó del P. Acosta se lo acreditó a otros autores indeterminados. Porque al P. Acosta debe Covarrubias no sólo la primera hipótesis $($ Perú $=$ nombre de un río), sino también la fantástica identificación de los reinos del Perú con el Ofir bíblico, teoría que el P. Acosta analiza -y desechaprecisamente en los caps. 13 y 14 del lib. I de su Historia a que Covarrubias hace alusión. Aunque es posible que esta pista se la proporcionara Aldrete, quien en el mismo lugar de su tratado remite al P. Acosta y a otras de las autoridades que, a este respecto, habría de citar Covarrubias. Pero no es éste el momento de analizar el problema específico de las dependencias bibliográficas, aunque bien merece un estudio particular ${ }^{\text {To }}$.

Creo que lo visto hasta aquí revela cuál fue el procedimiento seguido por Covarrubias en relación con los indoamericanismos que figuran en su diccionario. Nuestro lexicógrafo se limitó a documentar en los cronistas que estaban cómodamente a su alcance un número reducido de las voces americanas que habian sido previamente seleccionadas como dignas de hallar cabida en su Tesoro, tal vez por su ya notable vitalidad dentro del español peninsular. Pero es indudable que Covarrubias no acudió a esas fuentes históricas con el propósito de buscar sistemáticamente en ellas un caudal apreciable de americanismos que fueran ya conocidos en España. $\mathrm{Si}$ así hubiese procedido, no habría ignorado el origen americano de la coca, rigurosamente establecido en los escritos -que él conocía- de Gómara, Gieza y el P. Acosta; ni habría creído que cacique fuese voz de la lengua mexicana; ni habría pasado por alto la pro-

75 Reconoce alli Aldrete su deuda: "Assi lo refiere Garcilaso Inca en sus comentarios que aun no están impressos, que por hazerme gracia me a comunicado". Y, en efecto, en el cap. 4 del lib. I de los Comentarios reales, figura esa historia con gran lujo de detalles.

76 Me ocupo parcialmente de él en la ponencia presentada durante la celebración del VI Congreso de la Asociación Internacional de Hispanistas, Toronto, 22-26 de agosto de 1977 . 
cedencia americana del maiz y de su nombre, reiteradamente consignada por los historiadores que tenía a la mano ${ }^{77}$. De igual manera, si Covarrubias se hubiera propuesto espigar cuidadosamente en las obras de esos cronistas las voces americanas que ya eran conocidas en España, no habría dejado de incluir en su diccionario términos como batata, cacao, caribe o incluso bejuco, todos ellos explicados con precisión en sus fuentes documentales. Ni tampoco habría dejado en el olvido a ciertos topónimos que, si bien no tan famosos en España como México, Perú o Cuzco, serían sin duda también conocidos y para los cuales sus fuentes bibliográficas le proporcionaban explicaciones etimológicas muy sugestivas: las etimologías de Guatemala, de Haiti y del lago Titicaca hubiera podido hallarlas en la Historia general de López de Gómara ${ }^{78}$; otras más, en la Historia natural del P. Acosta. Pero el mundo americano quedaba todavía un tanto distante y al margen de los intereses científicos de la mayor parte de los eruditos peninsulares. Covarrubias, al menos, espigó con mayor acuciosidad las fuentes informativas referentes a otros ámbitos culturales, más próximos al saber renacentista, como el árabe, el hebreo y el románico, además - por supuesto- del grecolatino.

JuAN M. Lope Blanch

Universidad Nacional Autónoma de México.

El Colegio de México.

it Gómara, Historia general, cap. 215, et al.; Aldorete, Origen, p. 110; Acosta, Historia, lib. IV, cap. 16; etc.

78 "Cuauhtemallan, que comúnmente llaman Guatimala, quiere decir árbol podrido, porque cuauh es árbol, y temali, podre. También podrá decir lugar de árboles, porque temi, de donde asimismo se puede componer, es lugar" (cap. 208; p. 225 del vol. 2). "Haiti quiere decir aspereza y Quizqueia, tierra grande" (id., 1, p. 64). "Tiquicaca... quiere decir isla de plomo... que [el plomo] se llama tiqui" (id., 2, p. 29). 